\title{
Comparison the Outcomes Between Normal Discharge and Early Discharge of Newborns in Tehran Najmieh Hospital for Five Years (2010-2015)
}

\author{
Enayatollah Nematkhorasani*
}

Jomhoori eslami-Najmiyeh hospital, Tehran, Iran.

\author{
*Corresponding author \\ Dr. Enayatollah Nematkhorasani MD.Ped, Gasterologist, Faculty of \\ Baghiyatallah University Medical of Sciences, Iran. Tel: +0989151103196; \\ E-mail: Khorasani@dr.com.
}

Submitted: 04 Aug 2017; Accepted: 08 Aug 2017; Published: 23 Aug 2017

\begin{abstract}
According to the any neonatal care centers, discharge the neonates before 48 hour of birth time is early discharge and after this time is normal discharge of course by consideration rules of normal Neonatal discharge. Early discharges increase re-admitted for: hyperbilirobinemia, sepsis, dehydration F.T.T, forgotten congenital anomalia in neonates. We decided to study about this matter in our babies
\end{abstract}

Method: Our study was retrospective researching on records of our patients. According to the definition of Normal and early discharge, we collected 2531 cases. We used from SPSS\&SAS info-2000 for analysis of datas.

Results: 1331 cases were Males\&1200cases were Females (no differentiation between them, $P>0.001$ ). 1271 cases were normal discharges\&1260cases were early discharges (no diff between them, $P>0.001$ ). The common complications for readmitted by sequences were:1-Hyperbilirobinemia 2-Dehydration, 3-Sepsis, 4-forgotten congenital anomalia, 5-F.T.T in two groups and no differentiation Between them P>0.001)

Conclusion: According to the our study, when we have considerated rule of standard discharges Then no differentiation between two groups of normal discharges \& early discharges for outcomes. However we careful attention to them at near visits (After 48 hour, next week, two next weeks and monthly for one year).

\section{Introduction}

The neonatal period is defined as less than 28 days of life and may be further subdivided into the very early (birth to less than $24 \mathrm{hr}$ ), early (birth to less than 7 days), and late neonatal periods (7 days To less than 28 days) [1-2]. The neonatal period is a highly vulnerable time for an infant, who is completing many of the physiologic adjustments required for extra uterine existence [3]. The high neonatal mortality \& morbidity rates arrest to the fragility of life during this period, in the USA of all deaths occurring in $1^{\text {st }}$ year, two thirds are in the neonatal period $[3,4]$. The annual rate of deaths during the $1^{\text {st }}$ year is unequaled until the 7 th decade [4]. An infant $\mathrm{s}$ transition from intrauterine to extra uterine life requires many biochemical and physiologic changes. Many of newborns special problems are related to poor adaptation because of asphyxia, premature birth, life-threating congenital anomalies, or the adverse effects of delivery $[3,4]$. Non-high risk healthy infants may be to the regular newborn nursery or be placed in the mother s room if the hospital has rooming in [4-5]. Early discharge $(<48 \mathrm{hr})$ or very early discharge $(<24 \mathrm{hr})$ may increase the risk of hospitalization for some complications for example: Icter, Dehydration, F.T.T, Sepsis, Missed congenital anomalia [5]. Early discharge needs careful ambulatory follow-up at home (visiting nurse) or in the office within $48 \mathrm{hr}$. Additional criteria for early discharge of term neonates have been developed by the American Academy of pediatrics and American College of Obstetrics and Gynecology (Table-1) [6,7].

Table 1: Recommendations for Early Discharge from the Normal Newborn Nursery:

1. Uncomplicated antepartum, intrapartum, postpartum courses

2. Normal vaginal delivery

3. Singleton at $38-42 \mathrm{wk}$ AGA

4. Normal vital signs $(\mathrm{RR}<60 \mathrm{~min}$, auxiliary $\mathrm{T} 36.1-37 \mathrm{C})$

5. Physical Examinations Normal

6. Evidence of parental knowledge, ability, and confidence to care for the baby at home

7. Avalilability of family and physician support (physician follow up)

8. Laboratory evaluations (VDRL, HBV, State screening, coombs test)

9. No social risks (History of child abuse, Domestic violence, Mental illness, Teen Mother, Homeles) 
Method

Our study was retrospective (observational) on records of our patients. We collected 2531 Cases. We analyzed our datas by Spss and SAS INFO-2000 (P>0.001).

\section{Results}

1331 cases were Males \& 1200 cases were Females. ( $P>0.001$, No diff between them). Our normal discharges were 1271 and early discharges were 1260 ( $\mathrm{P}>0.001$, No diff between them). 2032 cases were term neonates and 499 cases were pre-term neonates. ( $\mathrm{P}>0.001$, significant diff between them). The common causes of re-admitted in two groups by sequences were:1-Hyperbilirubenima (1236 cases), 2-Dehydration (801 cases), 3-Sepsis (400 cases), 4-Forgotten congenital anomalia (5 cases), 5-F.T.T ( 4 cases), 6-Overlape ( 89 cases). ( $\mathrm{P}>0.001$ significant diff between them).

\section{Conclusion}

Normal discharge is discharge of neonates after $48 \mathrm{hr}$ of birth and early discharge is Discharge before $48 \mathrm{hr}$ of birth. Denote in any textbooks that early discharges caused re-admitted them for some complications, for example: hyperbilirubenemia, Sepsis, Dehydration, F.T.T, Congenitalanomalia. But according to the study, showed that no differentiation between these two groups.

About complications and causes re-admitted particularly when we have considrated to standard rule of neonatal discharge.

\section{References}

1. Barbara J Stoll (2016) overview of mortality \& morbidity. The fetus and the neonatal infant. Nelson Textbook of pediatrics. Chapter 93.20th Edition. Sunders 671-672.

2. Barbara J Stoll. (2016) the Newborn Infant. The fetus and neonatal infant. Nelson textbook of pedia Trics. Chapter 94, 20th Edition. Sunders 675-676.

3. Barbara J Stoll (2016) Nursery Care. The fetus and the neonatal infant. Nelson Textbook of pediatrics .chapter 94.4, 20th Edition. Sunders 681-682.

4. Friedman MA, Spitzer AR (2004) Discharge criteria for the term newborn. Pediatrclin N Am 51: 599-618.

5. Cooper c. baby and question and answer (2004) Dorling Kindersley limit. London P25-37.

6. Denne CD, Fanaroff Avroy A (2006) Nursery of neonate. Neonatal-Perinatal Medicine.Vol.1, 8th Edition. Mosby, Philadelphia 661-679.

7. Henry Seidel Beryl Rosenstein Ambadas Pathak Wendell McKay (2006) Primery Careof newborn. Mosby 100-107.
Copyright: (C2017 Dr. Enayatollah Nematkhorasani. This is an openaccess article distributed under the terms of the Creative Commons Attribution License, which permits unrestricted use, distribution, and reproduction in any medium, provided the original author and source are credited. 